\title{
Atuação do Movimento dos Atingidos por Barragens (MAB) no ciclo neodesenvolvimentista
}

\author{
Acting of the Movement of People Affected by Dams (MAB) in the neodevelopmentalist cycle \\ Papel del Movimiento de Afectados por Represas (MAB) en el ciclo neodesarrollista
}

Recebido: 22/07/2021 | Revisado: 29/07/2021 | Aceito: 31/07/2021 | Publicado: 10/08/2021

\author{
Andreza Aparecida Franco Câmara \\ ORCID: https://orcid.org/0000-0001-8761-2197 \\ Universidade Federal Fluminense, Brasil \\ Universidade Federal Rural do Rio de Janeiro, Brasil \\ E-mail: andrezafranco@id.uff.br \\ Alessandra Dale Giacomin Terra \\ ORCID: https://orcid.org/0000-0003-3311-121X \\ Universidade Federal Fluminense, Brasil \\ E-mail: alessandraterra@id.uff.br \\ Paulo Brasil Dill Soares \\ ORCID: https://orcid.org/0000-0003-0724-8271 \\ Universidade Federal Fluminense, Brasil \\ E-mail: paulobrasildillsoares@id.uff.br
}

\begin{abstract}
Resumo
$\mathrm{O}$ presente artigo pretende refletir sobre o protagonismo do Movimento dos Atingidos por Barragens (MAB) nas dinâmicas do desenvolvimento, a partir da categoria da sustentabilidade. Adotou-se como metodologia a revisão de literatura, análise de documentos públicos e o estudo de caso das experiências realizadas pelo MAB, no conjunto de ações de enfrentamento e resistência frente à conjuntura neoliberal adotada a partir da década de 1990. Concluiu-se que embora os conflitos sociais envolvendo a implantação de represas ganhem cada vez mais espaços na mídia e haja uma evolução na atuação MAB, o modelo de "avaliação de risco" das décadas de 80 e 90 persiste quando se trata dos reassentamentos involuntários. Isto porque o instrumental teórico-conceitual naturaliza as populações, representandoas como obstáculos ao progresso e não as tratam como atores sociais capazes de discutir direitos e interesses.

Palavras-chave: Movimentos sociais; Movimento dos atingidos por barragens; Sustentabilidade; Neodesenvolvimentismo.

Abstract

This article intends to reflect on the leading role of the Movement of People Affected by Dams (MAB) in the dynamics of development, based on the sustainability category. The methodology adopted was a literature review, analysis of public documents and a case study of the experiences carried out by the MAB, in the set of actions to confront and resist the neoliberal situation adopted from the 1990s onwards. social conflicts involving the implementation of dams gain more and more space in the media and there is an evolution in MAB's performance, the "risk assessment" model of the $80 \mathrm{~s}$ and $90 \mathrm{~s}$ persists when it comes to involuntary resettlements. This is because the theoretical-conceptual instrument naturalizes populations, representing them as obstacles to progress and does not treat them as social actors capable of discussing rights and interests.
\end{abstract}

Keywords: Social movements; Movement of those affected by dams; Sustainability; Neodevelopmentalism.

\section{Resumen}

Este artículo pretende reflexionar sobre el rol protagónico del Movimiento de Afectados por Represas (MAB) en la dinámica del desarrollo, con base en la categoría de sostenibilidad. La metodología adoptada fue una revisión de la literatura, análisis de documentos públicos y un estudio de caso de las experiencias realizadas por el MAB, en el conjunto de acciones para enfrentar y resistir la situación neoliberal adoptada a partir de la década de 1990. Conflictos sociales relacionados con la implementación de represas gana cada vez más espacio en los medios y hay una evolución en el desempeño del MAB, el modelo de "evaluación de riesgos" de los años 80 y 90 persiste cuando se trata de reasentamientos involuntarios. Esto se debe a que el instrumento teórico-conceptual naturaliza a las poblaciones, las representa como obstáculos al progreso y no las trata como actores sociales capaces de discutir derechos e intereses.

Palabras clave: Movimientos sociales; Movimiento de afectados por represas; Sustentabilidad; Neodesarrollismo. 


\section{Introdução}

O presente artigo pretende refletir, a partir da categoria de sustentabilidade, sobre o protagonismo do Movimento dos Atingidos por Barragens (MAB) nas dinâmicas do desenvolvimento e da conjuntura neoliberal adotada, notadamente, a partir dos anos 1990.

A vinculação de empreendimentos hidrelétricos a um discurso triunfante, em que a usina hidrelétrica aparece como sinônimo de progresso e desenvolvimento, não é uma novidade na história das usinas hidrelétricas no Brasil. Sevá (2004) pontua que a mídia tende a sobrevalorizar os pontos positivos das hidrelétricas, como por exemplo, geração de emprego e renda, aumento da arrecadação tributária, enquanto os pontos negativos são minimizados, quando não ignorados, tais como, liberação natural de dióxido de carbono e metano para a atmosfera, obstáculos artificiais ao transporte de materiais até às zonas costeiras, diminuição dos materiais que deveriam atingir essas zonas, modificações na estrutura das praias e das linhas de costa, transformação dos movimentos tidais e regimes hidrológicos sazonais, temperatura da água e salinidade, distribuição dos nutrientes a biota, dentre outros.

Parte-se do pressuposto de que a reestruturação das atividades desempenhadas pela população impactada passa pela construção de um novo modelo jamais antes experimentado pelos deslocados, que arca com o ônus de um processo excludente de desenvolvimento, que, em certa medida, passa a ser combativo pelo MAB.

Esse trabalho parte de problemas substantivos na análise das reformas neoliberais proporcionadas nas últimas três décadas com a privatização dos serviços de infraestrutura e a reestruturação de setores chaves no desenvolvimento econômico brasileiro, que culminaram na efetivação das mudanças sugeridas por organismos nacionais e internacionais na política energética na América Latina e no Brasil, destacadamente na matriz hidroelétrica. $\mathrm{O}$ artigo também resgata a trajetória histórica do MAB e o enfretamento ao modelo de crises e constâncias assumidas pela conjuntura capitalista, que irradia seus espectros no Estado brasileiro.

\section{Metodologia}

Esta pesquisa deu-se por meio de metodologia qualitativa, ou seja, através de métodos em que se tem destaque a interpretação do pesquisador sobre os processos e fenômenos observados (Pereira, Shitsuka, Parreira \& Shitsuka, 2018). Tratase de estudo de caso, centrado nas experiências realizadas pelo MAB, com análise de documentos oficiais e revisão de literatura, buscando refletir sobre o conjunto de ações de enfrentamento e resistência de tal movimento social frente a conjuntura neoliberal adotada a partir da década de 1990.

Buscou-se neste estudo investigar não um fenômeno ou fato específico, mas as ações coletivas e processos sociais por traz da atuação do movimento, utilizando-se abordagem de observação direta, uma vez que "implica na atividade de um pesquisador que observa pessoalmente e de maneira prolongada situações e comportamentos pelos quais se interessa, sem reduzir-se a conceituar somente por meio das categorias utilizadas por aqueles que vivem estas situações” (Jaccoud e Mayer, 2018, p.255).

Utilizou-se método hipotético-dedutivo, cotejando com a base empírica e a literatura sobre o tema a hipótese de que, embora os conflitos sociais envolvendo a implantação de represas ganhem cada vez mais espaços na mídia e haja uma evolução na atuação MAB, o modelo de "avaliação de risco" das décadas de 1980 e 1990 persiste quando se trata dos reassentamentos involuntários. Isto porque o instrumental teórico-conceitual naturaliza as populações, representando-as como obstáculos ao progresso e não as tratam como atores sociais capazes de discutir direitos e interesses. 
A discussão sobre os impactos sociais e ambientais das barragens e o processo político que permeia suas implantações tem mobilizado pesquisadores (Vainer, 2007), que refletem sobre os resultados nos quais esses projetos provocam no cotidiano de populações surpreendidas com a mudança não apenas do curso de rios, controlados pelas barragens, mas, com o curso de suas próprias vidas, do seu modo de produção, das relações sociais e históricas entre eles e seu território.

\section{Resultados e Discussão}

\section{A trajetória do Movimento dos Atingidos por Barragens}

As perspectivas teóricas abordadas neste trabalho se refere às ações coletivas incrementadas por meio de movimentos sociais, destacadamente pela atuação do movimento dos atingidos por barragens (MAB) no ciclo neodesenvolvimentista brasileiro iniciado pelo governo do Presidente Fernando Collor de Mello, ampliado pelo Governo FHC e consolidado pela rubrica Programa de Aceleração do Crescimento (PAC) dos governos progressistas que o sucederam na estratégia de adoção de grandes projetos que geram grandes impactos negativos desconsiderados pelos governantes quando seus concepções de progresso associados ao desenvolvimento econômico em detrimento do desenvolvimento social.

Dirceu Benincá (2011) informa que com a construção da hidrelétrica de Itaipu, no estado do Paraná, os agricultores desapropriados pela intervenção hidráulica criaram o Movimento Justiça e Terra cujo objetivo principal foi reivindicar a justa indenização de suas propriedades. Segundo Vainer e Araújo (1992), a Usina de Itaipu representa nesse período um símbolo da engenharia nacional e da potência do Estado brasileiro, mas também consagra o início da luta dos atingidos por barragens no Brasil. A partir de 1979, os expropriados de Itaipu protagonizaram no cenário nacional e internacional estratégias informativas e mobilizações dos agricultores, apoiadas em ações de religiosos e militantes da Comissão da Pastoral da Terra (CPT) na mobilização com a presença dos sindicatos de trabalhadores rurais mais combativos. Todavia, uma nova medida foi tomada preventivamente: as populações ameaçadas de deslocamento organizaram-se antes da construção da barragem.

Nos anos seguintes a sua criação, a Comissão Regional de Atingidos por Barragens do Alto Uruguai (CRAB) insere suas reivindicações nas cinco regiões, dentre elas a exigência de "terra por terra" para a criação de políticas voltadas para o reassentamento dos atingidos. A estratégia era fortalecer a coletividade, em oposição à prática das empresas responsáveis pelos empreendimentos que primavam por negociações e indenizações individuais. Em fevereiro de 1983, em Carlos Gomes, distrito atingido pela barragem de Machadinho, na Romaria da Terra surge o emblemático slogan: "Águas para vida não para morte" e iniciasse o apelo à questão ambiental.

Estas circunstâncias levaram a Eletrosul Centrais Elétricas S.A. (Eletrosul) e a Comissão Regional dos Atingidos por Barragens (CRAB) a firmarem um acordo de 1987. Sob a ótica dos dirigentes da CRAB, o acordo representava o reconhecimento e a aceitação da construção de barragens de Itá e Machadinho (VAINER, 2002, p. 8). Sob a tônica do Setor Elétrico brasileiro, o pacto legitimou a CRAB como representante dos atingidos para compor uma série de condições a serem executadas nos projetos, tendo como conquistas relevantes às negociações coletivas com a presença de representantes da CRAB, reassentamento coletivo e vinculação do cronograma de obras após a etapa de negociações coletivas.

A partir de 1987, os conflitos se estabeleceram em torno do cumprimento do acordo em decorrência da crise econômica vivida pelo País, com reflexos no Setor Elétrico, que suspendeu a execução de projetos hidrelétricos desenvolvidos pela Eletrosul.

No final dos anos 70, após as duas crises do petróleo (1973 e 1979) e com o colapso do modelo de Bretton Woods ${ }^{1}$, o enfraquecimento do pacto autoritário e a aliança empresários com governos militares e o surgimento do movimento pela

${ }^{1}$ Bretton Woods uma pequena localidade no nordeste dos Estados Unidos, em julho de 1944, reuniu representantes da Aliança das Nações Unidas, que reunia
os países em guerra contra o eixo fascista (inclusive o Brasil), reuniram-se na de para empreender uma das mais audaciosas iniciativas em engenharia social
tentadas até então ou mesmo, na verdade, desde então. Tratava-se de criar regras e instituições formais de ordenação de um sistema monetário internacional 
redemocratização do País, com o apoio de grupos empresariais que fomentavam o fim da estatização da economia, houve o declínio do modelo nacional-desenvolvimentista e o processo de liberalização política e da instauração da nova ordem democrática, entre 1975-1985 (Diniz, 2010).

A visão liberal foi um forte componente ideológico que permeou o novo regime constituinte democrático baseado na livre iniciativa do mercado. As elites empresariais defenderam na etapa de elaboração da Carta Constitucional de 1988, uma maior participação do Estado e o fortalecimento do mercado com a permanência de programas desenvolvimentista. Mesmo com o forte lobby do mercado e da livre iniciativa, a partir de 1989, foram realizados encontros para analisar e discutir a questão ambiental após a obrigatoriedade do Estudo de Impacto Ambiental (EIA), do Relatório de Impacto Ambiental (RIMA) e do licenciamento ambiental no processo de construção de grandes empreendimentos.

Em abril de 1989, realizou-se na cidade de Goiânia/GO, o I Encontro Nacional de Trabalhadores Atingidos por Barragens, com a participação de representantes dos impactados de várias regiões do Brasil. O encontro foi organizado pela CRAB e pela Central Única dos Trabalhadores (CUT), com o apoio da CPT e da Comissão Pró-Índio de São Paulo (CPI), e objetivou socializar experiências de organização de luta contra o modelo econômico hegemônico, principalmente no campo energético, hasteado no Brasil no período de ditadura militar.

Dentre as principais conclusões verificou-se que o "inimigo" era o mesmo: o neoliberalismo e o autoritarismo na gestão do Setor Elétrico, que precisaria ser combatido não através de movimentos isolados pelas regiões do País, mas com um corpo orgânico que representaria as demandas e lutas de todos os atingidos, como destaca Lidia Rebouças (1992) a criação do movimento se dá "através de reuniões de grupos de trabalhos, assembleias e discussões a partir de informações sobre os processos políticos subjacentes à construção da usina, trazidas por aqueles mediadores". Nasce o Movimento dos Atingidos por Barragens (MAB) com atuação nacional e identidade de luta caracterizada, sobretudo, por práticas que recaem desde a desobediência civil até ameaças de sequestro de funcionários como forma de pressão junto aos órgãos centrais do poder, com três contextos políticos diferentes: a politização, a sindicalização e a legitimação do movimento.

O movimento ao posicionar-se frente aos projetos desenvolvimentistas após a sua nacionalização questionou a centralização de poder nas mãos do governo federal, em regra, para definir a política energética, ou seja, onde, quando e como serão implantados os grandes empreendimentos energéticos no País, conforme acentua Martins $(1988$, p. 11) "os grandes projetos contribuíram decisivamente para despertar o demônio da política, adormecido na alma dos humilhados e desvalidos da terra, que põe em questão mais do que esses projetos".

\section{A nacionalização do MAB e o combate à política neoliberal}

No contexto econômico, o Brasil após 1990, com o governo de Fernando Collor, representou a ruptura de um ideário nacional-desenvolvimentismo, e radicalizou-se com a presidência de Fernando Henrique Cardoso (FHC), redefinindo a agenda pública com prioridade no binômio: estabilização econômica e reformas estruturais. Criou-se programas de privatizações com a abertura comercial, liberalização dos fluxos financeiros e a defesa da disciplina fiscal e da contingência da intervenção do Estado no mercado (Diniz, 2011).

Tendo por base a economia neoclássica e a hegemonia do neoliberalismo em escala mundial, o governo de FHC introduziu uma nova ordem centrada no primado do mercado a partir de 1995, com a execução de reformas econômicas e constitucionais, sustentado por uma coalizão de centro-direita e a implantação de políticas baseadas no modelo fundamentado

capaz de superar as enormes limitações que os sistemas então conhecidos, o padrão-ouro e o sistema de desvalorizações cambiais competitivas, haviam imposto não apenas ao comércio internacional mas também à própria operação das economias domésticas. Buscava-se, assim, definir regras comuns de comportamento para os países participantes que, se poderiam por um lado contribuir para que eles atingissem níveis sustentados de prosperidade econômica como nunca havia sido possível antes, exigiriam, por outro lado, que abrissem mão de pelo menos parte da sua soberania na tomada de decisões sobre políticas domésticas, subordinando-as ao objetivo comum de conquista da estabilidade macroeconômica. (Carvalho, 2014, p. 01) 
no mercado, apresentando como resultado o aprofundamento do processo de globalização e das políticas governamentais de estabilização e reformas, principalmente aquelas que fomentavam a privatização, a abertura comercial e a liberalização dos fluxos financeiros. Concomitantemente, após 1991, o MAB ganhou dimensão nacional através da interlocução como outros movimentos sociais e organizações de esquerda nacional e internacional com o objetivo de combater o processo de privatizações ocorrido no Brasil, após a adesão ao Consenso de Washington, em 1989.

Em Brasília, promoveu-se o I Congresso Nacional de Atingidos por Barragens cujo propósito era a revisão da matriz energética, na busca de fontes alternativas de energia, além de solucionar os problemas socioambientais gerados com a implantação de novas barragens. O Movimento participou da Conferência das Nações Unidas sobre o Meio Ambiente e Desenvolvimento, conhecida por ECO-92 ou Rio-92, realizada entre os dias 3 e 14 de junho de 1992, na cidade do Rio de Janeiro, a fim de estabelecer articulações com a Comissão Mundial de Barragens, ampliando os debates sobre as questões ambientais.

Com o acirramento da política neoliberal nesse período, o MAB aprofundou as reflexões sobre o paradigma energético brasileiro, construindo uma participação efetiva dos atingidos. Em março de 1997, o MAB realizou o I Encontro Internacional de Atingidos por Barragens na cidade de Curitiba (PR). O evento contou com a participação de delegações representando movimentos sociais e Organizações Não-Governamentais (ONGs) de vinte países, firmando no calendário o dia 14 de março como a data oficial para combate internacional de lutas contra as barragens elaborando a Declaração de Curitiba.

A década de 2000 é marcada por uma grave crise no Setor Elétrico devido, principalmente, à falta de investimentos federais na área, o que resultou no racionamento de eletricidade no País. Após as eleições presidenciais de 2002, com a esquerda no comando da nação, o Setor Elétrico Brasileiro (SEB) foi objeto de nova reforma, marcada pela presença de empresas privadas que atuam no mercado por meio de concorrência direta com várias sociedades de economia mista de controle majoritário, quer da União, quer dos Estados-membros.

\section{A Esquerda chega ao governo e continua o modelo insustentável de desenvolvimento}

Rosa (2013) considera que o Novo Modelo do Setor implantado em 2004, avançou em relação ao planejamento setorial, porém não sanou os problemas provenientes do período de privatização do Setor. O cancelamento dos contratos de concessão entre as empresas geradoras estatais e as distribuidoras, no ano de 2003, gerou perdas para o Grupo Eletrobras, que suportou o encargo de vender energia mais barata para os consumidores livres e as grandes indústrias intensivas em energia que, atualmente, consomem $30 \%$ da energia elétrica gerada no País.

O primeiro conjunto de medidas destinadas ao SEB no governo de Luiz Inácio Lula da Silva se deu com o primeiro pacote de investimento e com a divulgação do Plano Plurianual (2004-2007), com valores destinados ao setor de energia que se aproximavam de $\mathrm{R} \$ 32$ bilhões, oriundos do setor estatal e privado. Após a divulgação do Plano Plurianual, o Ministério de Minas e Energia (MME) editou um documento intitulado Modelo Institucional do Setor Elétrico.

Diante do modelo lançado após 2004, o MAB posicionou-se dando maior destaque a uma democracia participativa, além de manter seu cronograma de ações e articulações. Em 2005, o MAB integrou-se à Assembleia Popular Nacional com o objetivo de difundir um projeto popular para o País. Nascem às inquietações sobre o preço da energia, quem são os destinatários e para quais setores é destinada. Nesse contexto, surgem slogans como: "O preço da luz é um roubo - a vítima é você!”; “Água e energia não são mercadorias”; “Água e energia são para a soberania”; “Energia para que e para quem?”.

Nos últimos anos, o MAB vem aprofundando o debate sobre o novo modelo energético, tecendo críticas severas sobre a dominação do capital nesse setor e debatendo o custo da tarifa social na energia.

A intensificação da luta do MAB norteou-se para a construção de princípios em torno das seguintes metas: i) fortalecimento da luta contra as barragens; ii) controle governamental na produção, distribuição e comercialização de energia; 
iii) ampliação dos serviços de energia para as populações não atendidas; iv) discussão sobre a natureza da energia com uma patrimônio nacional e não simples mercadoria para os grupos empresariais que a comercializam; v) arranjo racional e atendimento das necessidades vitais do povo brasileiro; vi) institucionalização da energia como direito do povo brasileiro; vii) tarifas subsidiadas para itens de bens e serviços, destinados à melhoria da qualidade de vida; viii) seleção da matriz energética para o atendimento das necessidades fundamentais da vida das presentes e futuras gerações; $i x$ ) superação do discurso da escassez de energia; $x$ ) disposição política de garantir a participação efetiva das classes em todos os processos de planejamento e organização da produção e distribuição da energia da sociedade brasileira.

Desse modo, o MAB ressurge a partir de um argumento social de combate a uma ameaça iminente: o modelo excludente energético. Durante a sua trajetória, o movimento se constituiu de um importante instrumento político com forte apelo ideológico de combate as práticas neoliberais implantadas durante as décadas seguintes a sua criação, com a formulação de propostas alternativas sobre a questão energética e do modelo de desenvolvimento socioeconômico aplicado no Brasil.

\section{A estrutura interna do MAB: existem líderes ou um coletivo fluído?}

Neste item, analisa-se, a partir da teoria dos novos movimentos sociais, a estrutura funcional do MAB e os seus efeitos para a consolidação de seus objetivos e dos processos decisórios a respeito de sua atuação contra os represamentos ocorridos após os anos 90.

Cervinski (2011) apresenta três propósitos defendidos pelo MAB enquanto movimento de combate ao processo ideológico de privatização das águas: $i$ ) natureza reivindicatória, uma vez que a luta pela conquista e garantia de direitos para os atingidos deve ser institucionalizada; ii) dimensão política, na medida em que debate as alternativas ao modelo energético desenvolvido no Brasil e no mundo; e, iii) apresenta caráter genuinamente democrático, pois a organização é criada pelos próprios atingidos com vistas à transformação social e como forma de resistência aos processos de conversão da água e da energia em mercadorias através de privatizações e hidrelétricas.

Os discursos dos novos movimentos podem, no decorrer de suas produções, criar antagonismos entre os atores, caracterizados por uma riqueza de argumentos políticos, que podem invisibilizar os aspectos chaves ao entendimento dos processos sociais. Por vezes, silenciar a voz do oprimido tem sido a principal estratégia do poder hegemônico em todo o mundo, o que não é diferente no caso dos atingidos por barragens.

A estratégia de silenciamento do dominado faz parte da construção do imaginário do mundo contemporâneo, no qual esse sistema nasce e permanece em torno desta lógica. É um processo que articula forças, oprime vozes esquecidas e apaga memórias para diminuir as resistências ao modelo energético postos pelo poder hegemônico no modo de produção capitalista. Visando combater essa tipologia de poder, o MAB é classificado como um movimento socioambiental e, apresenta como principais metas: $i$ ) a resistência contra a construção de barragens que provocam danos sociais e ambientais; ii) a reivindicação de que a construção de barragens seja realizada com a concordância da população atingida; iii) a defesa da permanência do povo na terra; $i v$ ) a garantia de justa indenização ou do reassentamento dos atingidos; v) a capacitação dos integrantes do movimento; vi) o estímulo a participação de novos militantes; vii) o debate e proposição de um novo modelo energético para o País, que prime pela utilização de fontes alternativas de geração de energia, acesso à energia para todos, com tarifas de baixo custo para os consumidores populares, dentre outros.

Com base nessas diretrizes definidas pelo movimento, percebe-se uma formação calçada na solidariedade a partir de um conflito claramente definido: a privatização do Setor Elétrico e o controle da energia e recursos hídricos através de ações efetivamente democráticas, tentando romper os limites do sistema em que ocorre a ação, não limitando-se apenas a formas amplas de protesto (Melucci, 1989). Dentre lutas estão o combate ao modelo de desenvolvimento capitalista e a implantação de outro modelo baseado em pilares de ampla participação popular, conforme se observa nos debates promovidos no Seminário 
Modelo Energético Brasileiro: Atualidades e Perspectivas, organizado pelo MAB e, tendo como convidado Franklin Moreira, que questionou o atual modelo de consumo energético mundial, baseado no padrão de vida norte-americano (MAB, 2014).

As ideais centrais do movimento, sua identidade e princípios direciona-o para uma organização interna fundamentada na formação de grupos de base, estruturados por cinco a dez famílias direta ou indiretamente atingidas por barragens, que se reúnem sistematicamente para estudar, debater e aprofundar estratégias de ação. Na prática, isso "significa organizar todos aqueles que moram nas comunidades atingidas e estão dispostos a lutar" (MAB, 2014). Participam desses grupos de base, não só as famílias que possuem terras nas comunidades afetadas, "mas também aquelas que de alguma forma dependem economicamente da comunidade atingida para viver ou do próprio rio” (MAB, 2014).

Benincá (2011) afirma que a organização interna desses grupos de base apresenta uma liderança exercida através de um coordenador, indicado pelos seus próprios integrantes. Seu papel além de incrementar estratégias contra a implantação da barragem na situação empírica, caberá, também, a indicação da coordenação municipal e regional, e, esse conjunto, uma vez organizado, indicará as respectivas coordenações estaduais e nacionais.

Além das coordenações existe uma direção articulada em grupos menores com a finalidade de encaminhar os trabalhos mais específicos, apresentando um modo de organização descentralizado. É um processo coletivo na lógica do consenso (Benincá, 2011). Existem, além dos grupos de base, setores ou equipes, responsáveis pela execução de atividades concretas e as coordenações estruturadas nos planos local, estadual e nacional.

Nesse tipo de movimento como o MAB busca-se novas formas horizontalizadas e descentralizadas, recusando o mando de indivíduos “superiores”. As decisões são discutidas em coletivos e, uma vez tomadas, são levadas nas vozes de todos os militantes e daqueles que são nomeados diante de um reconhecimento comum dos militantes do movimento, como mediadores externos ou coordenadores de coletivos.

Nesse novo modo de organização mais fluído à participação e à expressão autodeterminada dos militantes torna fértil um campo para a reprodução de redes de movimentos sociais, cada vez mais articuladas às perspectivas da criação do que se configuram por "rede de redes" ou por "movimento de movimentos", representando formas complexas de comunicação e de intercâmbios entre os atores sociais. Trata-se, na visão de Melucci (1991), de características das redes de movimentos sociais, conectadas a circuitos de solidariedade lideradas não por uma leadership ou liderança concentrada, mas difusa, com estrutura policéfala, reticulada, segmentada. O problema do sistema de redes é que às vezes elas contém elos mais fortes, como por exemplo, lideranças, militantes, pesquisadores, organizações de referência, que se sobrepõe aos liderados.

A instância máxima de articulação do movimento é o Congresso Nacional, realizado a cada três anos e consiste em um momento de reflexão interna, de consolidação dos princípios norteadores e objetivos, além de ser o palco para as discussões sobre novas estratégias e correção de rumo de outras.

Recentemente, o congresso passou a ser chamado de Encontro Nacional. Essa estratégia visa assegurar coesão e consenso no movimento que, por vezes, enfrenta momentos de descrença e severa repressão política. Desse modo, compreender como se formam as relações sociais e as estruturas de poder nos novos movimentos é uma forma de perceber como são alicerçadas as relações de reciprocidade e de compartilhamento entre os membros. É preciso analisar como é constituída a autonomia dos membros mais excluídos, por vezes escondidos sob o título genérico de "povo" no discurso de mediadores.

Nessa experiência de desenraizamento das heranças, tradições, culturas e identidades, que somente pode ser suturada com uma política de extensão dos direitos e valores, é preciso o "reconhecimento recíproco", já salientado por Arendt (1988), desenvolvendo principalmente aspectos como ver e ser visto, ouvir e ser ouvido, tanto individual quanto coletivamente, no campo das minorias e também das maiorias, abolindo do exibicionismo político que reduz e aniquila a capacidade de representação comum e esquece de suas agendas a reivindicação e luta por direitos daqueles qualificados como vulneráveis. 
Em relação aos recursos financeiros para subsidiar as estratégias de lutas, o MAB conta com contribuições dos próprios atingidos, colaboração de entidades como igrejas, cooperação internacional, organismos não-governamentais e recursos do poder público. Há uma promessa do governo federal em criar a Política Nacional de Direitos das Populações Atingidas por Barragens e a criação de um Fundo Nacional para a viabilização da Política e dos planos de recuperação e desenvolvimento das comunidades atingidas.

\section{Hoje, quem são os atingidos por barragens?}

Para entender a atuação do MAB é preciso traçar um perfil de quem são os atingidos por barragens atualmente no Brasil. Com a política energética implementada após o PAC, a opção governamental priorizou regiões com grande potencial de exploração hidráulica e direcionado pelos inventários de bacias de rios, que geralmente cortam mais de um município e/ou estados. Nesses inventários, o licenciamento ambiental não é feito de todo o complexo hidráulico, mas de trechos, evitando assim que em um único projeto se formem legiões de deslocados.

Por vezes, as áreas atingidas por uma usina hidrelétrica compreendem grupos sociais heterogêneos, estando presente populações urbanas, populações rurais, compostas por grandes, médios e pequenos proprietários agrícolas, camponeses sem terra, arrendatários, parceiros, possuidores (com ou sem título/contrato), pequenos e médios comerciantes; empresários da indústria, do comércio, do turismo, trabalhadores destes empreendimentos, assalariados, autônomos, dentre outras atividades, das mais variadas faixa etária e de diversas escolaridades, com origens étnicas e religiosas diversas; há ainda populações tradicionais como ribeirinhos, pescadores, quilombolas, nações indígenas, etc. A noção de atingido, segundo Vainer (2008, p. 40), "diz respeito, de fato, ao reconhecimento, leia-se legitimação, de direitos e de seus detentores", variando no tempo e no espaço.

No Relatório da Comissão Especial do Conselho de Defesa dos Direitos da Pessoa Humana (CDDPH), publicado em 2010, o conceito atingido aparece como o conjunto de indivíduos, famílias, grupos sociais e populações que, de modo geral, vivencia as dimensões seguintes: i) o processo complexo de mudança social, que envolve deslocamento compulsório de população e alterações na organização cultural, social, econômica e territorial; ii) o sofrimento dos impactos não apenas da implantação do reservatório, mas também das demais obras e intervenções associadas ao empreendimento, tais como: canteiro, instalações funcionais e residenciais, estradas, linhas de transmissão etc.; iii) os variados tipos de impactos, como deslocamento compulsório (de proprietários e não proprietários), a perda da terra e de outros bens, a perda ou a restrição de acesso a recursos necessários à reprodução do modo de vida, a perda ou a redução de fontes de ocupação, renda ou meios de sustento, a ruptura de circuitos econômicos; $i v$ ) o recebimento de deslocados pelas comunidades e pelas populações anfitriãs; v) os efeitos a jusante da barragem suportados pelas comunidades e pelas populações após o enchimento do reservatório.

O Relatório ainda considera como atingidos aqueles que tiveram perdas decorrentes das alterações impostas aos circuitos e às redes de sociabilidade, quando caracterizada a ruptura de relações sociais e quando consideradas as dimensões culturais e a identidade dos grupos, das comunidades e das famílias atingidas. Além disso, as perdas de natureza afetiva, simbólica e cultural, imateriais e intangíveis e, por isso mesmo, não passíveis de quantificação ou de simples indenização financeira, devem ser consideradas como objeto de ampla e aberta discussão e negociação.

Quanto aos povos indígenas e às comunidades tradicionais, ainda segundo o Relatório, devem ser considerados suas especificidades culturais e seus direitos históricos, constitucionais e reconhecidos por convenções internacionais.

Historicamente, o conceito de atingido se modificou nas últimas décadas e ganhou status de direito humano a partir do reconhecimento e da legitimação de garantias desses indivíduos, dos grupos sociais e das comunidades, ao longo da trajetória das lutas, intensificadas a partir da década de 1990 com a criação do MAB. Todavia, o capital ainda adota definições que restringem a dimensão de conquistas desses atores por meio da compensação estritamente econômica que, de início, entendia 
atingido como proprietário. Vainer (2008) denomina essa noção como "concepção territorial-patrimonialista", que, no Brasil, durante muitos anos, foi adotada na implantação de grandes empreendimentos, especialmente de projetos hidroelétricos.

Algumas empresas que compõem o Setor Elétrico utilizam, ainda como estratégia, a concepção territorialpatrimonialista por meio de seus Departamentos de Patrimônio Imobiliário, os quais, ao apresentarem o instituto da desapropriação por utilidade pública, não configuram "propriamente impactos, nem atingidos, e menos ainda qualquer coisa que possa ser entendida como direitos dos atingidos; [pois] o que há é o direito de desapropriação por utilidade pública exercido pelo empreendedor" (Vainer, 2008, p. 42-43), pagando aos expropriados o justo valor de suas propriedades para remover as populações, compreendidas como obstáculos ao desenvolvimento.

Na década de 80, com a criação do Conselho Nacional do Meio Ambiente (CONAMA) e com a edição da Resolução $\mathrm{n}^{\circ}$. 001/1986, passou-se a exigir Estudo de Impacto Ambiental (EIA) e seu respectivo Relatório de Impacto Ambiental (RIMA) para esse tipo de empreendimento. A Eletrobrás adotou como paradigma a metodologia proposta pela Companhia Energética de São Paulo (CESP). As ações ambientais se estruturavam, por meio do Manual de Estudos Ambientais dos Sistemas Elétricos, em quatro planos: a) levantamentos; b) desapropriações; c) enchimento; e d) utilização do reservatório, alterando parcialmente o cenário.

A incorporação nas audiências públicas da população atingida - para levantamentos, prospecções e estudos destinados à identificação, à interpretação e à previsão dos efeitos que cada ação do empreendedor pode causar ao ambiente e as condições socioeconômicas e culturais dos atingidos também passou a ser um item obrigatório na instalação de usinas hidrelétricas.

Segundo Vainer (2008) outra concepção que ainda se verifica é a hídrica, isto é, o atingido é apenas o inundado. A concepção hídrica, estimulada pela legislação vigente, adota como forma de compensação o pagamento de Imposto sobre Serviço de Qualquer Natureza (ISSQN), considerados como municípios atingidos apenas aqueles que terão suas áreas total ou parcialmente inundadas. As regiões a jusante e a montante do lago, embora sofram consequências com a instalação da barragem, não recebem qualquer retorno financeiro. A "consequência da concepção hídrica tem sido a sistemática omissão diante dos efeitos do empreendimento na vida de populações não atingidas pelas águas, efeitos que podem ser, e em muitos casos têm sido, dramáticos" (Vainer, 2008, p. 45).

Com o propósito de combater esse efeito patrimonialista/hídrico de atingido, Vieira (2011) classifica o MAB como um movimento engajado nas lutas sociais concretas, que integra a Via Campesina, idealizando, como no caso das outras entidades, pontos sobre a questão agrária, em confronto ao modelo dominante.

Zen (2007) observa que no caso dos integrantes do MAB, existe um reforço na questão identitária, muito embora não exista lei que defina quem é atingido por barragem, o movimento apresenta um reconhecimento mútuo entre seus integrantes e a sociedade, considera que essa identidade é resultado de uma organização coletiva do movimento. Por isso, a identificação de seus integrantes como atingido ganha uma dimensão cultural. A identidade do grupo passa a ser construída a partir da diferenciação do "outro". Zen (2007) afirma que as identidades se configuram na forma de representação, estando presentes características próprias do interior do grupo específico; uma vez identificados os grupos aliados, geralmente pertencentes também a mesma classe social, serão diferenciados dos grupos e classes antagônicas.

Vainer (2002) afirma que, embora os conflitos sociais que envolvem a implantação de represas ganhem cada vez mais espaços na mídia e não obstante haja uma evolução na atuação do MAB, o modelo de "avaliação de risco", das décadas de 80 e 90, persiste quando se trata dos reassentamentos involuntários; isto porque o instrumental teórico-conceitual naturaliza as populações, representa-as como obstáculos ao progresso e não as trata como atores sociais capazes de discutir direitos e interesses. Verifica-se, assim, uma curiosa inversão: as populações humanas (o meio socioeconômico) atingidas pelo projeto 
de engenharia passaram a fazer parte do ambiente (Vainer, 2002). Assim, do ponto de vista social, cada represa a ser instalada remete a um processo social marcado por relações específicas e a uma nova configuração social² .

Como destacado na trajetória do movimento, a noção de identidade é lapidada a partir do confronto com um determinado processo de expropriação organizado pelas "forças hegemônicas do mercado" em oposição ao movimento de militantes que sofrem processos semelhantes, foi um passo importante para o contorno das principais lutas e a configuração atual do MAB, conforme se apresentará abaixo.

\section{A opção do MAB pela defesa das bacias do Norte e do Nordeste}

De acordo com o Dossiê "A repressão aos defensores de direitos humanos e movimentos sociais no Brasil" (MAB, 2011), existiam em 2010 aproximadamente 2.000 barragens. Até 2011, dessas barragens, 625 se encontravam em operação, sendo 139 de grande porte com mais de 30 MW; 233 barragens com potência ente 1 e 30 MW; 153 barragens com capacidade abaixo de $1 \mathrm{MW}$; e, cerca de 1.530 micro barragens. Os relatórios do Plano Nacional de Eletrificação e do PAC preveem, até 2015, a construção de mais 494 grandes barragens. Segundo a Eletrobras, também existe um potencial que poderá vir a ser explorado em pequenas centrais hidrelétricas, em torno de 942 novas barragens ${ }^{3}$.

O Ministério de Minas e Energia estimava, em 2007, que 50 grandes barragens se encontram em construção e, até 2010 (segundo mandato do Presidente Lula) foram projetados a construção de mais 70 grandes barragens. De acordo com dados do PAC 2, em 2014, são 344 empreendimentos de geração de energia elétrica (PAC 2, 2014). Porém, os mesmos planos do governo em nenhum momento apontam o número de famílias atingidas, não existe nenhum estudo real por parte do governo federal quanto ao número de famílias a serem remanejadas. O MAB possui estimativas de que este número chegue a 100 mil famílias atingidas pelos projetos do atual governo.

Conforme dados da Agência Nacional de Energia Elétrica (ANEEL, 2014), atualmente o Brasil possui 87.968 KW de compulsoriamente de suas terras devido à construção de barragens; isto corresponde a 300 mil famílias. Nesse mesmo relatório, o movimento aponta que a cada 100 famílias deslocadas, 70 não receberam nenhum tipo de indenização. Em relação a área atingida, os dados são: 34 mil $\mathrm{Km}^{2}$ de terra fértil foram inundados pelos reservatórios, o que corresponde a 3,4 milhões de hectares. A capacidade instalada em operação proveniente de seu potencial hidráulico, o que corresponde a 1.140 usinas hidrelétricas, sendo 63,101\% da capacidade de energia produzida. Uma das denúncias apresentadas pelo MAB é que o setor industrial continua sendo o maior consumidor da energia hidráulica produzida.

O movimento denuncia que ao construir uma usina, o capital envolvido nessa implantação, organiza estudo do potencial energético elaborado pela Eletrobrás e datado da década de 1970. Uma vez identificado local de construção da barragem, iniciam-se os estudos e levantamentos técnicos, sendo um deles o levantamento socioeconômico do local. Estes estudos são feitos ou contratados pela própria empresa interessada na construção da barragem e serão utilizados posteriormente no processo licitatório e na elaboração do EIA/RIMA. Desse modo, a mesma empresa interessada na construção da barragem faz os estudos e define os conceitos que baseiam o levantamento. Assim, o quantitativo de atingidos sofrem variações dado o campo de interesse e previsão orçamentária para realizar das desapropriações.

\footnotetext{
${ }^{2} \mathrm{O}$ termo "configuração social" é usado aqui como um modo de agregação dos indivíduos: como e por que eles formam entre si certa dinâmica e as mudanças que se sucedem a partir de fatores internos e externos a essa configuração (Elias e Scotson, 2000).

${ }^{3}$ Os dados trabalhados serão considerados como uma continuação dos três mandatos dos governos petistas (2003 a 2014).
} 
No processo de licitação realizado pelo ente federativo, em regra, há a parceria com o MME, estes dados tornam-se legalizados e as empresas passam a ter responsabilidades frente ao governo federal, ANEEL e justiça ${ }^{4}$. Assim, os atingidos não cadastrados passam a ser considerados como "ilegais" pela empresa gestora do empreendimento 5 .

O MAB em seu Dossiê (2011) exemplifica o caso do remanejamento de 800 famílias em decorrência do enchimento do lago das barragens de Castanhão/CE (300) e Acauã/PB (500). De acordo, com dados do MME, as obras das barragens foram concluídas e as questões sociais não foram superadas, as famílias não receberam indenização; além das perdas materiais existem também as simbólicas. Os responsáveis pelo empreendimento atribuem as condições climáticas como fator para essa remoção rápida. Além de fatores externos às obras, é recorrente que as empresas responsáveis pela construção e pela operação ingressem no Judiciário para cumprir o poder de polícia inerente a esse tipo de obra pública. O MAB denuncia ações tais como incêndios das residências e ação policial para evitar que o atingido regresse a seu imóvel.

Dentre as perdas simbólicas, o movimento lista os casos de famílias que, mesmo permanecendo em suas terras têm suas comunidades desestruturadas. Nestes casos, via de regra, os atingidos a jusante e a montante da barragem não são contabilizados pelo Setor de Patrimônio da empresa responsável pelo empreendimento, o que significa que os números oficiais não correspondem à realidade.

O MAB cita o caso do Grupo Cassol, em Rondônia, que construiu várias Pequenas Centrais Hidrelétricas (PCHs) e desviou o Rio Branco. Estima-se que a jusante da construção moravam quatorze aldeias com aproximadamente duas mil pessoas, o rio secou e pôs fim ao único meio de transporte das comunidades e também sua fonte de alimentação.

Verifica-se que as empresas responsáveis por esses empreendimentos hidráulicos adotam formas de tratamento diferenciado entre as populações atingidas por barragens, com o argumento de "negociações amigáveis", as empresas aproveitam-se da mobilização fragmentada dos atingidos, enfraquecendo as negociações sobre quais bens, patrimônio e valores serão indenizados e sua respectiva avaliação quantitativa monetária.

O movimento denuncia a criação por parte dessas empresas de falsas organizações e representantes, chamados às vezes de "Comissões Negociadoras", onde participam empresários, delegados, políticos (prefeitos) e, a presença dos atingidos é cerceada. Em certos casos isolados através da pressão na grande mídia, os atingidos têm, no máximo, conseguido colocar lideranças para acompanhar essas famílias.

\section{Considerações Finais}

$\mathrm{O}$ fato de que as populações locais e regionais foram impactadas pelos processos de reestruturação territorial decorrente da implementação de hidrelétricas, revelando a lógica de apropriação econômica do recurso hídrico, adotada pelo Setor Elétrico do País, principalmente, após a fase de privatização desse segmento. Retomando a era desenvolvimentista com os grandes projetos de investimento, referentemente às negociações e soluções para as questões socioambientais decorrentes da instalação das obras em questão.

Os impactos sociais com a remoção e a realocação dos atingidos por barragens não resultam tão somente da atuação imposta pelo Estado, numa lógica descendente, tão pouco das ações ou omissões dos empreendedores e seus técnicos, ou de falhas do planejamento e execução do projeto. Porém, derivados de um processo repleto de tensões e conflitos de interesses. A solução advém da resultante das forças envolvidas no processo conflituoso.

\footnotetext{
${ }^{4}$ Segundo Dossiê MAB (2011) o custo das questões sociais e ambientais previstos nos orçamentos das obras giram em torno de 0,5 a $3,0 \%$ do total da obra, mas em diversas barragens onde a população se organizou para reivindicar os direitos humanos a moradia digna, a produção digna e cultural, os gastos com essas questões sociais passaram para a orbita de 25 a $30 \%$ do orçamento do projeto.

${ }^{5}$ No processo indenizatório, as famílias reconhecidas pelas empresas são oferecidas tradicionalmente três opções: (i) carta de crédito; (ii) indenização em dinheiro; ou, (iii) reassentamento em grandes áreas para àquelas barragens que estejam localizadas em áreas rurais.
} 
Historicamente, esses pleitos adquiriram o status de "direitos", que vêm sendo reivindicado através do Movimento dos Atingidos por Barragens, com as primeiras negociações iniciadas na bacia do Rio Uruguai (SC/RS), no final da década de 1970, ganhando força nacional após a década de 1990 com a institucionalização do MAB. Todavia, com a proliferação dos projetos hidrelétricos na primeira década do século XXI, percebemos uma alteração de estratégia do movimento, que, agora prioriza determinados empreendimentos, em regra, aqueles de maior impacto ambiental e nas comunidades tradicionais, devido ao modelo de organização descentralizada de comando e de pautas construídas a partir da mobilização dos próprios atingidos.

O que se percebe nesse caso é a incorporação do recurso midiático dos conflitos hidrelétricos, ou seja, com a dimensão continental do País e o planejamento e execução de vários projetos hidrelétricos ao mesmo tempo, com recursos oriundos do PAC, o movimento parece não dar conta de conscientizar, negociar e lutar em todos os casos. Tendo que optar pelos projetos de maior impacto e com maior visibilidade de suas conquistas.

\section{Referências}

Arendt, H. (1988). Da revolução. Trad. Fernando Vieira \& Caio N. de Toledo. Ática; Ed. UnB.

Benincá, D. (2011). Energia \& cidadania: a luta dos atingidos por barragens. Cortez.

Carvalho, F. C. (2004) Bretton Woods aos 60 anos. Novos Estudos, 70. https://christypato.files.wordpress.com/2008/09/cardim-fernando-bretton-woods-60anos.pdf.

Cervinski, G. (2011). Crise capital e privatização da água. discurso ideológico para a privatização da água. Entrevista com (MAB Brasil) à radio mundo real FM: 19 de julho de 2011. <http://www.radiomundoreal.fm/Crise-capital-e-privatizacao-da?lang=es>

Diniz, E. (2011). O contexto internacional e a retomada do debate sobre desenvolvimento no Brasil contemporâneo (2000/2010). DADOS - Revista de Ciências Sociais, 54(4), 493-531.

Diniz, E. (2010). Empresariado Industrial, Representação de Interesses e Ação Política: Trajetória Histórica e Novas Configurações. Política \& Sociedade. Revista de Sociologia Política, 9(17), 101-139.

Elias, N., Scotson, J. L (2000). Os estabelecidos e os outsiders: sociologia das relações de poder a partir de uma pequena comunidade. Trad. Vera Ribeiro, Zahar.

Jaccound, M. \& Maye, R. A observação direta e a pesquisa qualitativa in Poupart, J., Deslauriers, J. P., Groulx, L. H., Laperrière, A., Mayer, R., \& Pires, Á. (2018). A pesquisa qualitativa. Enfoques epistemológicos e metodológico.

MAB. Energia para quê e para quem? <http://www.mabnacional.org.br/menu/proposta.html>.

MAB. Produção de energia na ótica popular. <http://www.mabnacional.org.br/menu/producao_energia.html>.

MAB. Organização. < http://www.mabnacional.org.br/organizacao>.

MAB (2013). MAB cobra de Lobão política nacional e fundo para os atingidos. Movimento dos Atingidos por Barragens, nov., http://www.mabnacional.org.br/noticia/mab-cobra-lob-pol-tica-nacional-e-fundo-para-os-atingidos>.

MAB. Seminário modelo energético brasileiro: atualidades e perspectivas. <http://www.mabnacional.org.br/noticia/soberania-nacional-discutida-no-seminrio-energia-da-regi-sudeste>.

Martins, J. S. (1988). A chegada do estranho: notas e reflexões sobre o impacto dos grandes projetos econômicos nas populações indígenas e camponesas da Amazônia. Anais do $46^{\circ}$ Congresso Internacional de Americanistas, Amsterdam.

Melucci, A. (1989). Um objetivo para os movimentos sociais? Luz. Nova, Trad.: Suely Bastos. 17, 49-66. <http://www.scielo.br/pdf/ln/n17/a04n17.pdf>

Melucci, A. (2001) A invenção do presente. Movimentos sociais nas sociedades complexas. Vozes.

Pereira, A. S., Shitsuka, D. M., Parreira, F. J., \& Shitsuka, R. (2018). Metodologia da pesquisa científica. UFSM. https://www.ufsm.br/app/uploads/sites/358/2019/02/Metodologia-da-Pesquisa-Cientifica_final.pdf

Rosa, L. P. (2013). Energia e setor elétrico nos governos Lula e Dilma. In SADER, Emir (org.). 10 anos de governos pós-neoliberais no Brasil: Lula e Dilma. Boitempo; FLACSO Brasil, 73-190.

Vainer, C. B. (2008). O conceito de "Atingido": uma revisão do debate. In ROTHMAN, Franklin Daniel. Vidas alagadas: conflitos socioambientais, licenciamento e barragens. UFV.

Vainer, C. B. (2002). Águas para a vida, não para a morte. Notas para uma história do movimento de atingidos por barragens no Brasil. In: Workshop Social Movements in the South, Center for International Affairs, Harvard University, 1-24.

Vainer, C. B. (1992), Araujo, F. G. B. Grandes projetos hidrelétricos e desenvolvimento regional. CEDI. 
Research, Society and Development, v. 10, n. 10, e98101018602, 2021

(CC BY 4.0) | ISSN 2525-3409 | DOI: http://dx.doi.org/10.33448/rsd-v10i10.18602

Vieira, F. B. (2011). Dos proletários unidos à globalização da esperança: um estudo sobre internacionalismo e a Via Campesina. Alameda.

Zen, E. L. (2007). Movimentos sociais e a questão de classe: um olhar sobre o Movimento dos Atingidos por Barragens. 211f. Dissertação (Mestrado em Sociologia), Universidade de Brasília, 〈http://bdtd.bce.unb.br/tedesimplificado/tde_busca/arquivo.php?codArquivo=2415>. 